\title{
AS BOAS MANEIRAS E A EDUCAÇÃO NA CONSTRUÇÃO DA SOCIEDADE MODERNA: UMA INCURSÃO NO PENSAMENTO DE JOHN LOCKE
}

\author{
Viviane de Lima ${ }^{1}$ \\ Carlos Herold Junior ${ }^{2}$ \\ Universidade Estadual do Centro-Oeste - PR
}

UNICENTRO

\section{RESUMO:}

O presente artigo tem por objetivo analisar o pensamento educacional de John Locke, mais especificamente, as questões referentes ao ensino das boas maneiras. Para tal, organizou-se as ideias divididas em três momentos. No primeiro, são estudadas as transformações históricas que influenciaram o pensamento educacional de John Locke. Em um segundo momento, levando-se em consideração sua obra Pensamentos sobre a Educação (PSE), mostrar-se-á alguns aspectos de uma boa educação, considerada por Locke como capaz de formar o gentleman. No terceiro momento, serão focalizadas as questões concernentes à educação das boas maneiras, buscando relacioná-las com o que Norbert Elias (1994) afirma ao analisar o processo civilizador que teve lugar na modernidade. Como resultado, observamos que a preocupação de Locke em formar o gentleman corrobora os achados de Norbert Elias, levando a crer que a educação lockeana se constituiu em um importante momento formativo da sociedade moderna.

Palavras-chave: John Locke; Educação; Boas maneiras; Gentleman; Norbert Elias; Costumes.

\section{GOOD MANNERS AND EDUCATION IN BUILDING MODERN SOCIETY: A INCURSION IN THE THOUGHT OF JOHN LOCKE}

\begin{abstract}
:
This article aims to analyze the educational thought of John Locke, more specifically, issues related to the teaching of good manners. To this end, we organized the ideas divided into three stages. At first, we studied the historical changes that influenced the educational thought of John Locke. In a second step, taking into consideration his work Some Thoughts on Education (PSE), we will show some aspects of a good education, regarded by Locke as able to form a gentleman. In the third phase, focused are the issues concerning the education of good manners, trying to relate them to what Norbert Elias (1994) states in analyzing the "civilizing process" that took place modernity. As a result, we see that Locke's concern in forming the gentleman confirms the findings of Norbert Elias, leading us to believe that the Lockean education constituted an important formative moment of the modern society.
\end{abstract}

Keywords: John Locke; Education; Good manners, Gentleman; Norbert Elias; Mores. 


\section{Introdução}

Este trabalho tem por objetivo analisar o pensamento educacional de John Locke (1632-1704), levando-se em consideração sua obra Pensamentos sobre a Educação (PSE). Mais especificamente, analisaremos as questões referentes ao ensino das boas maneiras, buscando demonstrar de que maneira o refinamento dos hábitos e das atitudes do indivíduo são importantes para construção do mundo moderno.

Pretendemos mostrar que esse refinamento dos hábitos, que esse cuidado com as boas maneiras que Locke apresenta na seção XXIII dos PSE, quando expõe a educação do Cavalheiro (gentleman) para a formação do novo homem, o homem de negócio, poderá ser melhor compreendido se utilizarmos as reflexões elaboradas pelo sociólogo Norbert Elias, que aborda os tipos de comportamento considerados típicos do homem civilizado Ocidental.

Este estudo é de caráter bibliográfico e será dividido em três momentos: 1)contextualização com algumas questões ocorridas na época do autor. Em seguida, iremos estudar a teoria educacional de Locke exposta nos PSE. Por fim apresentaremos as questões das boas maneiras da referida obra, relacionado-as com o que Norbert Elias afirma sobre tal questão.

\section{A Inglaterra e as lutas políticas e filosóficas assumidas por John Locke}

Como afirma Lago (2002) "para melhor compreender um homem e seu pensamento, é necessário entender não só o momento em que ele viveu, como também a posição por ele assumida e o tempo que o precedeu" (LAGO, 2002, p. 19). Assumimos como importante essa advertência para iniciar nossas reflexões a partir de um panorama do contexto no qual viveu e pensou John Locke.

John Locke nasceu no seio de uma família burguesa e participou das lutas da burguesia inglesa. À época, isso significava lutar contra a teocracia anglicana e suas teses legitimadoras, ou seja, a idéia de que o rei possuía poder absoluto e determinava, entre outras coisas, a religião que a nação devia seguir (MARTINS; MONTEIRO, 1978). Locke se posicionava contra essas teses e em sua filosofia política e educacional buscava justificar e defender os interesses da ascendente burguesia.

Segundo Cambi (1999), foi no século XVI que iniciou, de certa forma, a modernidade com suas características: a secularização, o individualismo, o domínio da natureza, o Estado moderno, a afirmação da burguesia e da economia de mercado capitalista: "confirmado e colocado essas características como estruturas de uma nova época histórica: da burguesia, da ciência, do capitalismo, do Estado moderno" (CAMBI, 1999, p. 243).

No século XVI, o velho e o novo ainda se defrontam, embora o "sentido de liberdade e de inovação se tenha tornado mais radical e mais geral" (CAMBI, 1999, p. 243). O retorno da leitura dos clássicos passa a ser um estímulo para uma criação nova e não mais imitação, uma vez que, a "cidade ideal [de Platão], agora, é substituída pela cidade real" (CAMBI, 1999, p.244).

A educação também passa por um processo de transformação que se observa nos terrenos político, religioso, ético, social e técnico. As transformações políticas ocorrem devido à criação do Estado moderno, capaz de impor um domínio da sociedade civil, diferente das formas de controle até então utilizadas (CAMBI, 1999).

Já as transformações religiosas ocorreram devido a Reforma e a Contra-reforma, pois, no século XVI renovou-se a educação religiosa e a formação do cristão, tencionando 
os compromissos da Igreja Católica. A ética, nessa época, tornou-se mais individualista, exigindo uma educação que almejasse a autonomia (CAMBI, 1999).

Abordando o contexto mais especificamente inglês, notamos que durante o século XVII, com o desenvolvimento do capitalismo passava-se por um momento de grande transição social, no qual estava presente a luta de poder de senhores feudais versus burguesia, provocando várias revoluções naquele país.

Operou-se assim, uma transformação econômica, social, cultural e política. Dentre os fatores que estiveram presentes, podemos destacar: a ascensão da Inglaterra no mercado internacional; o enriquecimento de uma parcela da população (burguesia e nova nobreza) que passou a monopolizar o comércio pela burguesia comercial. O êxodo rural provocado pelo aparecimento da indústria tecelã e da nova nobreza, que passou a produzir matéria-prima explorando os camponeses que ainda restava; e a constituição de uma sociedade estratificada (LAGO, 2002, p. 20).

Além dos fatores econômicos, os fatores de ordem religiosa também contribuíram para essa transformação, operando como suporte ideológico. Desde Henrique VIII na Inglaterra a religião oficial era a anglicana, que é utilizada como apoio ao absolutismo, sendo chefiada pelo rei inglês. A sua base social compreende os grupos sociais favorecidos pelo Estado formado pela grande nobreza e pela burguesia (LAGO, 2002).

No século XVII, a burguesia e a nova nobreza já estavam fortalecidas graças às políticas mercantilistas. Pois em 1588 a burguesia média, passou a ser contra o Estado absolutista, vendo neste um obstáculo ao seu desenvolvimento. Com isso, passou a lutar pelo poder político, utilizando-se das tradições Parlamentares existentes na Inglaterra desde o século XIII (LAGO, 2002).

Desse modo, no século XVII, como estava fortalecida, a burguesia poderia solidificar o seu domínio sobre a nação, e com a Revolução Gloriosa (1688) chegou-se ao fim dos conflitos e derrota do absolutismo. É nesse contexto que John Locke estava inserido. É nele que sua filosofia buscou justificar e defender os interesses da burguesia, expressando seus pensamentos e seus ideais, que também se materializaram em um pensamento educacional.

No campo especificamente educacional observamos o surgimento de novos procedimentos através dos quais a sociedade passou a disciplinar e vigiar o indivíduo buscando reprimí-lo e controlá-lo, ao mesmo tempo em que o formava para liberdade. Esta era a nova educação moderna, instrutiva, controladora, racionalizada em todas as suas ações e nos seus processos, assumindo um importante papel social e civil. Para Cambi, foi entre o fim dos Seiscentos e inicio dos Setecentos, que teve início a essas mudanças das técnicas educativas e escolares e se formaram esses modelos pedagógicos, culturais e educativo-escolares, que se opõem ao racionalismo e oferecem uma nova imagem dos processos formativos, ligando aos processos empírico-naturais, como fará Locke (CAMBI, 1999).

\section{Os novos desafios e os Pensamentos Sobre Educação (PSE) (1693).}

Os PSE, segundo Cambi (1999), oferecem um significativo testemunho do século XVII da sociedade inglesa, de suas mudanças econômicas e políticas, aceleradas pela passagem da Inglaterra de estado feudal para monarquia parlamentar e de agrícola em direção a Revolução Industrial, bem como com a emergência de novos grupos sociais, a 
começar pela burguesia, que assumiu um papel relevante até conquistar a hegemonia no país.

Esta obra de John Locke discorre, especificamente, acerca da problemática relacionada à educação. Trata-se de várias cartas que Locke escreveu enquanto estava na Holanda e foram endereçadas a seu amigo, o Sr. Edward Clarke. Em vários aspectos da teoria educativa de Locke é possível perceber que sua vida sempre esteve vinculada a educação, seja em seu modo de ganhar a vida ou nas cartas com conselhos educativos dirigidos a seus amigos (ENGUITA, 1986).

Ao tomarmos contato com o pensamento educacional de Locke, percebemos que ele entende que a educação deveria ser voltada para a vida, não consistindo em aperfeiçoar os jovens para as ciências, devendo ela, antes, abrir as mentes, preparando-os para desenvolver suas capacidades a serem utilizadas durante sua vida (LOCKE, 1986). Dessa forma, podemos perceber que Locke buscava a mudança de comportamento dos jovens. Assim, afirmara que deveria-se cuidar da formação do cavalheiro desde cedo, uma vez que através da educação que esse seria conduzido ao caminho correto (LAGO, 2002).

Observamos que ele possuía uma visão de educação que rompia com a ideia de transcendência e com os dogmas tradicionais, criticando os racionalistas que defendiam a existência de ideias inatas na mente humana. Para John Locke as crianças nascem como uma tábula rasa, a mente "como papel em branco" no qual nada se encontra escrito (ENGUITA, 1986, p.18). Deste modo, poderia-se imprimir qualquer coisa ou quaisquer verdades ao afirmar que "a capacidade é inata, mas o conhecimento adquirido" (LOCKE, 1978, p. 146).

Podemos perceber a importância que Locke atribuiu à educação, ao afirmar que "nove em cada dez homens são o que são, bons ou maus, úteis ou inúteis para a sociedade devido à educação que receberam" (LOCKE, 1986, p.31). Afirmara que, para o homem ser educado ele deveria receber uma ação educacional que visasse o disciplinamento do corpo e do espírito, pois aquele que "não dirige seu espírito sabiamente nunca seguirá o caminho reto, e aquele que não tiver o corpo são nunca avançará por ele" (LOCKE, 1986, p.31). Dessa forma, refere-se, em especial, à educação do cavalheiro (gentleman).

Locke apresentou, então, um novo modelo de homem para poder acompanhar as exigências da nova sociedade: o homem de negócios. Ele seria um indivíduo que soubesse se portar na sociedade, que tivesse bons hábitos e que possuísse um bom relacionamento com as pessoas para poder ser bem sucedido. Locke apontou o que considerava ser o ideal de homem a ser alcançado, e buscou demonstrar a formação adequada para se chegar a esse ideal. Sua proposta é a de formar um homem virtuoso, o homem racional, capaz de conduzir sua vida como cidadão conhecedor das leis, capaz de governar e de cuidar dos seus próprios interesses que, na maioria das vezes, eram materiais.

O filósofo valorizava a vida doméstica na medida em que depois dos primeiros anos de existência, os pais seriam os responsáveis pela escolha do preceptor que estaria em contato direto com a criança, devendo proteger o futuro cavalheiro (gentleman) contra os maus hábitos e maus exemplos. Caberia ao preceptor observar o comportamento dos meninos, apreciar suas faltas, inspirando-lhes o gosto pelo estudo. Deveria apontar o caminho correto a criança (LAGO, 2002).

Cambi (1999) afirma que para o processo educativo do futuro gentleman, conforme Locke, devia-se seguir alguns princípios para melhor ensinar-se os jovens, como: raciocinar com as crianças como forma de ensino; dar prioridade a formação da práticamoral e enfatizar a experiência aguçando a curiosidade natural da criança. 
Nessa perspectiva, Locke afirmava que o processo educativo deveria começar desde cedo e basear-se nos aspectos físico, moral e intelectual para disciplinar o corpo e o espírito para o autocontrole (LAGO, 2002). O aspecto moral é um dos principais objetivos da educação em Locke, o que levaria a criança a submeter os próprios desejos e as paixões à razão, ensinando que tudo deve ser obtido por causa de sua utilidade e não por ser agradável. Lago afirma que o que interessava para Locke na formação do homem:

[...] é inculcar princípios, formar hábitos que continuarão exercendo seu beneficio pelo resto da vida, tendo em vista um homem virtuoso e não um escravo ou um libertino. Que o homem tenha, desde cedo, o domínio sobre suas inclinações, saiba resistir a inoportunidade do prazer ou da dor verdadeiros fundamentos da felicidade e do bem viver assim como a educação, todos os nossos atos devem estar em favor de atitudes mais nobres (LAGO, 2002, p.98).

É através da formação de bons hábitos e pela disciplina dos desejos, que segundo Locke, adquiria-se a virtude. Para a autoridade dos pais, Locke sugeria que o temor e o respeito deveriam ser o primeiro domínio sobre seu espírito; e o amor e a amizade mais tarde nos anos mais maduros (LOCKE, 1986). Entretanto, Locke via com ressalvas a utilização dos castigos, pois afirmava que "as crianças mais castigadas são as menos aptas a ser os melhores homens"(LOCKE, 1986, p. 75), mas os vê como necessários, desde que fossem utilizados em momentos oportunos e sem excesso, para que o espírito da criança não fosse humilhado.

Segundo Lago (2002) a formação intelectual não era vista por Locke como o principal aspecto no processo educacional. Locke criticava a educação formalista, pois essa raramente forma para a vida. Sugere, assim, a necessidade de um novo modelo de vida, apontando que o que interessava ao gentleman era ter um conhecimento de caráter mais geral, e desenvolver suas capacidades através de exercícios para saber utilizá-las quando necessitar. Para alcançar esse objetivo, vinculava a instrução com o prazer e a utilidade, desenvolvendo as crianças através de jogos, fábulas e memorização de lições para exercitar a mente desde cedo, dando ênfase à matemática para o desenvolvimento do raciocínio.

\section{As boas maneiras no pensamento educacional de John Locke}

O sociólogo Norbert Elias (1993) apresenta questões fundamentais de "como os homens se tornaram educados, e começaram a tratar-se com boas maneiras" (RIBEIRO, 1994, p.9), ou seja, ele investiga como se iniciou o desenvolvimento da gentileza, da cortesia, dos modos de conduta típicos do homem civilizado ocidental, vendo neles sustentáculos para as construções sociais e políticas do mundo moderno (ELIAS, 1994). Ele expõe a idéia de como o comportamento dos povos ocidentais mudou após a Idade Média, abrindo caminho à compreensão do que ele denomina de "processo civilizador", buscando entender a transformação dos comportamentos e das necessidades do controle e da proibição para o equilíbrio das forças que impulsionam as relações sociais:

[...] isto não implica que estejamos, como já alertamos antes, na expectativa de encontrar o 'começo' do processo civilizador. Será tarefa mais que suficiente para nossos fins atuais tentar a curta jornada da fase medieval para a primeira moderna, em uma tentativa de compreender o que realmente aconteceu aos seres humanos nessa transição (ELIAS, 1994, p.76). 
Nessa perspectiva, Elias formula sua teoria tomando como base as transformações nos padrões europeus de comportamento à mesa, as funções corporais, de violência, na transição para a modernidade, pois ocorre durante o longo período em que abrange a transição da Idade Media à sociedade Moderna. Elias realiza tal análise, buscando demonstrar como surgiram as regras mais elementares de comportamento - não escarrar, não comer com as mãos, não colocar a bota em cima da mesa por exemplo. O sociólogo afirma que "o papel fundamental desempenhado nesse processo civilizador por uma mudança muito especifica nos sentimentos de vergonha e delicadeza, acaba mudando o padrão que a sociedade exige e proíbe" (ELIAS, 1994, p. 14). O que Elias busca frisar é o fato de que "mesmo na sociedade civilizada, nenhum ser humano chega civilizado ao mundo e que o processo civilizador individual que ele obrigatoriamente sofre é uma função do processo social" (ELIAS, 1994).

Normalmente, entende-se por civilizado a suavização de maneiras, polidez e boas maneiras, mas Elias (1994) afirma que o padrão de bom comportamento na Idade Média era representado por um conceito bem claro, o conceito de Courtoisie, que segundo Elias, resumia a autoconsciência aristocrática e o comportamento socialmente aceitável nessa época, pois, preceitos sobre a conduta às refeições tinham grande importância, "comer e beber nessa época ocupava uma posição muito mais central na vida social do que hoje" (ELIAS, 1994, p.76). Já que esta se tratava a um determinado lugar da sociedade, de como as pessoas se comportavam na corte, na qual a cortesia distinguia como uma espécie de um código de comportamento, principalmente os círculos cortesãos que gravitavam em torno das grandes cortes feudais. (ELIAS, 1994). Porém, a cortesia perde seu status social após o estabelecimento de uma nova aristocracia e de grandes mudanças comportamentais passando a empregar as boas maneiras de civilização.

O sociólogo se refere a vários tratados de boas maneiras, principalmente o de Erasmo de Rotterdam, Da civilidade em crianças escrito em 1530, para demonstrar as mudanças gradativas que se deram no comportamento dos indivíduos neste período histórico. Com essas ações, o que a classe alta queria era se distinguir das demais através das suas boas maneiras. Esses manuais de etiqueta, destinavam-se a um determinado público, geralmente, pessoas de classe alta, tendo maior sucesso devido ao grande interesse dos burgueses (ELIAS, 1994).

Elias afirma que os livros sobre boas maneiras são de grande valor se analisados os modos de comportamento, observando em todas as idades o que cada sociedade esperou de seus membros:

\footnotetext{
Mostra-nos com exatidão o que estamos procurando - isto é, o padrão de hábitos e comportamento a que a sociedade, em uma dada época, procurou acostumar o indivíduo. Esses poemas e tratados são em si mesmo instrumentos diretos a esses modos de comportamento que a estrutura e situação da sociedade onde vive tornam necessários. E mostram ao mesmo tempo, através do que censuram e elogiam, a divergência entre o que era considerado em épocas diferentes, maneiras boas e más (ELIAS, 1994, 95).
}

No nosso entendimento, a análise empreendida por Elias (1994) sobre o "processo civilizador" vem ao encontro da preocupação que John Locke apresenta a respeito do refinamento dos hábitos que o indivíduo deve adquirir para se tornar o homem ideal. Pois, 
Locke afirmava que há necessidade de formar um novo modelo de homem através de uma nova educação, que seria a educação do gentleman.

Locke apresenta nos PSE alguns hábitos de refinamento que o gentleman deveria desenvolver, deixando claro, "que não vejo nenhuma razão para oferecer uma educação a quem não seja filho de um cavalheiro" (ENGUITA, 1986, p.16). Nessa perspectiva, o indivíduo passava a adquirir desde cedo esse refinamento, aprendendo as regras necessárias para se comportar corretamente na nova sociedade. Com o auxilio de um preceptor cuidadosamente escolhido, o futuro gentleman deveria aprender esgrima, equitação, dança e as boas maneira, além de aprender um oficio manual (ENGUITA, 1986).

O filósofo afirmava que a graça que torna os movimentos agradáveis consiste no acordo entre a ação realizada e seu espírito, ou seja, a sinceridade, "as ações que emanam naturalmente deste espírito bem formado nos agradam também porque são suas expressões sinceras, por ser manifestação natural de suas disposições interiores do espírito" (LOCKE, 1986, p.91), enquanto que a imitação, a não espontaneidade das ações, causa a falta da beleza por não ser natural, pois deixa transparecer um desacordo entre a ação exterior e as disposições secretas do indivíduo:

O tutor deve, pois vigiar este defeito com mais eficácia quando é, como já citei, uma falta adquirida, o resultado de uma educação mal entendida, um defeito pouco frequente e ao qual estão sujeitos unicamente os que se vangloriam de serem bem educados, e não querem passar por ignorantes, como de fato são, conforme a moda e com boas maneiras da vida social. Se não me engano, este defeito provém com frequência da insuficiência das recomendações de um professor, que dá, negligentemente, regras e expõe exemplos, sem unir a prática às suas instruções, sem obrigar o aluno a repetir a ação perante seus olhos, para que possa corrigir o que for inconveniente ou forçado. O professor deve insistir até que o aluno se aperfeiçoe de maneira que a ação passe a ser habitual e fácil (LOCKE, 1986, p.92).

Em relação aos movimentos e a atitude do corpo, o professor de dança ensinaria, quando fosse o momento mais conveniente, mas, deveria ensinar o menino a dançar o mais cedo possível, para que assim, através da dança se tornasse um menino confiante, embora, enquanto fossem pequenos, não deveria se exigir muita perfeição nas regras durante as cerimônias de cortesia:

[...] Como a dança, me parece o melhor remédio dar, aos alunos, confiança e correção, estimulando-os a buscar em sociedade as pessoas mais experientes, que, creio eu, irão ensiná-los a dançar antes possível. Porque, através da dança e na graça exterior do movimento, proporcionado à criança, irá aprender pensamentos e maneiras viris, mais do que qualquer outra coisa. (LOCKE, 1986, p.93).

Essa qualidade da dança, necessária para o cavalheiro, adquiria-se pelo exercício, e demandaria certo tempo e trabalho, mas que lhe daria um ar viril e a segurança que convem aos jovens, devendo seguir o direcionamento de um professor que saiba ensinar os movimentos graciosos, "creio que nunca será demais ensinar-lhes a dançar uma vez que tenham a idade e o vigor necessário" (LOCKE, 1986, p.259). 
Além de tudo isso, para Locke, o jovem deveria ser bem educado para bem se portar nos bailes. Quando estivesse pronto, estaria preparado para se portar na sociedade e estabelecer as relações necessárias e fundamentais para o sucesso dos negócios. Dessa forma, podemos afirmar que o baile seria o fim de uma boa educação, pois seria o que proporcionaria para toda a vida o hábito dos movimentos graciosos.

Outro fator importante a ser evitado para que os meninos adquirissem maneiras elegantes, são as más companhias, pois as crianças eram vistas como aquelas que imitavam as pessoas que os rodeavam (LOCKE, 1986). O filósofo afirmava que qualquer que fossemas lições "de boa educação, que recebam todos os dias, nada terá tanta influência sobre sua conduta como a companhia dos que convive e as maneiras dos que lhe rodeiam", uma vez que, tanto as crianças, como os homens admiram e tomam como exemplo pessoas que os rodeiam, e como uma espécie de "camaleões" imitam constantemente suas maneiras, isso ocorre principalmente com crianças que aprendem "melhor as coisas que vê, do que as coisa que ouve" (LOCKE, 1986, p.95). Para o autor, o exemplo e a sociedade têm mais influência que todos os preceitos que todas as regras e todas as instruções (LOCKE, 1986).

Notamos que a qualidade que mais conviria para se tornar um cavalheiro era a boa educação visível nas boas maneiras. Para especificar essa idéia, Locke pondera que, existem duas maneiras do indivíduo se tornar mal educado: a timidez, e a falta de reserva. Para se evitar tais defeitos deveria-se seguir a prática constante de uma única regra: não ter má opinião nem de si mesmo nem dos demais. Sendo a primeira parte desta regra o cuidado com a excessiva segurança em si mesmo, pois não deveria ter de si mesmo uma opinião tão vantajosa, ou seja, sentir-se superior as outras pessoas, preocupando-se somente com seu próprio mérito. Assim, recomendava que recebesse modestamente as homenagens que lhe são devidas, mas deveria estimar-se o suficiente para recebê-las sem embaraços, sem demonstrar nas ações desordem no comportamento demonstrados através de movimentos deselegantes, uma vez que é normal acontecer com pessoas quando se encontram diante de estranhos e de superiores, serem tomadas por uma "rústica timidez". Isso ocorre devido a desordem que surge em seus pensamentos, em suas palavras, em seus olhares; perdem a cabeça a tal ponto que não conseguem fazer nada, ou ao menos não com liberdade e a graça que agrada e que os tornam pessoas atrativas (LOCKE, 1986, p.197). Para o filósofo, poderia-se curar esse defeito através do hábito contrário, frequentando a sociedade, conversando com estranhos e com pessoas de qualidade, pois "nada pode curar este defeito da educação, se não a mudança frequente de companhia e buscar a sociedade das pessoas que estão acima de nós" (LOCKE, 1986, p.197). Esse defeito viria da excessiva preocupação com a conduta que devemos ter para com os demais.

A outra maneira de ser mal educado, segundo Locke consistia em não parecer demasiadamente preocupado em agradar, ou em demonstrar respeito às outras pessoas. Para se evitar esses defeitos precisava estar disposto a nunca ofender os outros, buscando encontrar o meio mais agradável e expressivo de demonstrar isso. A primeira dessas qualidades, a não timidez, qualificaria seus possuidores de urbanos e a segunda, a demonstração de respeito, de polidos (cortês). A cortesia é a graça, a conveniência no olhar, na voz, nas palavras, e nos movimentos, em gestos, em toda a atitude que faria com que se triunfasse no mundo, passar tranquilidade ao mesmo tempo em que encantasse as pessoas com quem se conversa. É a linguagem pela qual se expressa um sentimento de sociabilidade que não se podia aprender e nem praticar, a não ser pela observação e imitação daqueles que eram, realmente, bem educados (LOCKE, 1986). 
Locke apontou nos PSE alguns defeitos vistos como contrários à cortesia, ou seja, a descortesia: a rudeza natural, que determinava a falta de tolerância, a falta de disposição em agradar o outro, sendo essa a característica do homem que não se importava em agradar as pessoas a sua volta. Segundo o autor, esta brutalidade choca e irrita a todos. Em vista disso, a cortesia buscaria corrigir essa falta de jeito natural e suavizar o caráter dos homens, para que, assim, pudessem adaptar-se com alguma tolerância às pessoas com quem se relacionavam.

Outro defeito é o menosprezo, a falta de respeito que se transmite através olhar, das conversas ou dos gestos. A expressão de desprezo é concebida como sempre desagradável. Também o espírito critico, a disposição a encontrar as faltas nas pessoas, pois os homens, mesmo culpados e/ou equivocados, ninguém gostaria de ver suas faltas expostas diante dos outros, o que levaria a um forte constrangimento que, definitivmente, afastariam essas pessoas daqueles que assim os tratassem. Devido a isso, se necessário, deveria-se se referir a eles de forma mais sutil e em um linguajar elegante, ou seja, manter um certo limite para não ser descortês. Também a ânsia de disputar é um dos defeitos contrário à cortesia, porque os arrastaria através de suas palavras e sua conduta a inconvenientes e a grosserias. Deste modo, para Locke o fato da felicidade consistir no prazer torna-se fácil entender porque os homens corteses são melhores acolhidos no mundo (LOCKE, 1986):

Aquele que sabe ser agradável com as pessoas com quem convive, sem se inclinar à bajulação servil e humilde, encontrou o segredo da arte de viver no mundo, de fazer-se apreciar em todas as partes, de ser bem acolhido. Por isso, seria necessário, acima de tudo, habituar, à cortesia, crianças e jovens. (LOCKE, 1986, p. 2001).

Outra falta contra as boas maneiras, considerada por Locke, é o indivíduo ser demasiado cerimonioso e obstinado em impor homenagens a pessoas que não lhe são devidas e que não podem aceitar sem se constrangerem, sendo isso inoportuno e, consequentemente, contrário à boa educação. Se o jovem tiver a disposição para esse defeito o filósofo pensa que seria necessário corrigí-lo prontamente, pois é durante a conversação, que se deve manifestar o respeito, estimação e benevolência para as pessoas, concedendo a cada uma delas a atenção que por cortesia lhes são devidas. Porém, conseguir isso sem que pareça adulação, hipocrisia ou humildade é uma grande arte que somente a razão, o bom senso e ser frequentador da boa sociedade podem ensinar. Para o autor essa qualidade seria muito preciosa na vida prática, por isso valeria a pena exercitá-la (LOCKE, 1986).

Sempre segundo Locke (1986), haveria outra espécie de descortesia muito fácil de desenvolver entre os meninos e que deveria ser corrigida: a disposição natural da criança de interromper as pessoas enquanto falam. Para ele, não haveria nada mais grosseiro que interromper em seu discurso um homem que fala, pois isso daria a entender que não estaríamos interessados no seu discurso, que estaríamos fatigados de escutar-lhe ou que pederíamos audiência apenas para nossos próprios discursos, concebendo-os (nossos pensamentos) como os únicos dignos de ser escutados. Não quer dizer que nunca se deva contrariar e emitir sua opinião nas conversas, e nos discursos, mas deveria-se ter o cuidado na maneira como contradizer. Ele recomenda que os jovens não se habituem a lançar suas próprias opiniões, até que seu interlocutor tenha terminado sua fala. É preciso vigiar os meninos com essa disposição, combater isso desde o começo e submetê-lo ao hábito contrário, em todas suas conversações. 
Locke afirma que entre os índios se observam mais cortesias, pois escutam em silêncio o outro até que termine sua fala, o que não ocorre na parte dita civilizada do mundo (LOCKE, 1986). O autor no que se refere à sociedade busca mostrar como a influência do meio em que se vive se estende mais longe, advertindo os preceptores e os pais, o seguinte:

Não são apenas maneiras polidas que se adquire na sociedade dos homens: o corante que dá a alguma coisa não fica na superfície, aprofunda-se ainda mais e, talvez, se fossemos considerar os costumes e religiões do mundo, reconheceríamos que a maioria dos homens tem esses pontos de vista e esses ritos, que, por eles, estão dispostos a dar a vida, ou seja, melhor dar a vida pelos costumes de seu país e pela prática constante de seus companheiros de nação, do que por uma convicção fundamentada. Faço essa observação para que possam ver a importância que todas as partes da sua vida têm para os seus filhos e para a sociedade que frequenta, e por isso é preciso ser cauteloso a esse respeito. A sociedade atua sobre ele com mais força que você (LOCKE, 1986, p.205)

Locke adverte que não convêm forçar os jovens na arte de adaptarem-se às regras de conduta. Bastaria levá-los a seguir as regras, ensinando-os a ser moderados, a ter bom caráter, e não faltar aos deveres; "a cortesia não consiste verdadeiramente senão em evitar na conversação que pareçam desdenhosos ou indiferentes para com as demais pessoas" (LOCKE, 1986, 203). Segundo Locke, se aprendessem isso, já conheceriam as formas mais credenciadas de cortesia. Porém, lembra-nos que essas formas são diferentes e mudam conforme os países, assim como a língua; e suas maneiras dependem da companhia que frequentam (LOCKE, 1986).

Deste modo, para Locke "as diferenças que se encontram nos costumes e nas atitudes dos homens, são devidas a sua educação mais do que a nenhuma outra coisa" (LOCKE, 1986, p.65), devido a isso deveria-se ter grande cuidado na formação e preparação da criança durante toda sua vida, visto que, quando obtém o bem ou o mal, a sua educação se dirigiria ao elogio e ou a censura.

Por conta de todas essas características, podemos entender que a educação do cavalheiro (gentleman) se completasse com as instruções de baile, de música, de esgrima, de equitação, com o aprendizado de um ofício, com viagens para estudar outras línguas, e ter contato e convívio com os mais diversos tipos de homens para se tornar o mais sábio possível e útil para a sociedade e, principalmente, para a satisfação de seus próprios interesses.

\section{Considerações finais}

Dessa forma, em decorrência das transformações econômicas e do surgimento da nova sociedade, Locke manifesta a necessidade de formar outro modelo de homem, "o homem de negócio" através de uma nova educação. E devido às transformações políticas, como o surgimento do estado moderno, por exemplo, e princípios éticos, culturais, sociais, religiosos da época, Locke pensa na educação e cortesia desse homem, pois, acaba por sugerir, em especial à burguesia, o refinamento dos hábitos através do ensino das boas maneiras, ao apresentar a boa educação do gentleman. Expõe a educação necessária para formar o burguês, indivíduo capaz de renunciar seus desejos e suas próprias inclinações e seguir o que sua razão the indica como melhor (CAMBI, 1999). Isso seria alcançado através da educação disciplinadora corpo e do espírito, desenvolvendo hábitos de boa 
educação, para adquirir uma correta linguagem e polidez nos comportamentos, ou seja, o indivíduo se adaptava à nova estrutura comportamental que estava relacionada às transformações sociais mais amplas que ensejavam o capitalismo, em um processo que, como vismo, Elias (1994) denominou de processo civilizador.

Para concluir, endossamos a importância de analisar as escolhas de John Locke pelo fato de elas demonstrarem como as particularidades educacionais menos visíveis no conjunto dos grandes debates políticos e filosóficos, relacionam-se com o constante e agudo processo de participar, conscientemente ou não, das lutas pelas transformações ou permanências das estruturas sociais.

\section{REFERÊNCIAS BIBLIOGRÁFICAS}

CAMBI, F. História da pedagogia. São Paulo: UNESP, 1999.

ELIAS, N. O processo civilizador. Uma historia dos costumes. Trad. Ruy Jungmann. Rio de Janeiro: Jorge Zahar Ed., 1994. 1v.

O processo civilizador. Formação do Estado e Civilização. Trad. Ruy Jungmann. Rio de Janeiro: Jorge Zahar Ed., 1993. 2v.

ENGUITA, M. F. Prólogo. In: LOCKE, J. Pensamientos sobre la educación. Madrid: Akal, 1986. p.09-23.

LAGO, C. Locke e a Educação. Chapecó: Argos, 2002.

LOCKE, J. Ensaios acerca do Entendimento Humano. São Paulo: Abril, $2^{\circ}$ edição, 1978. (Coleção Os Pensadores).

Pensamientos sobre la educación. Madrid: Akal, 1986.

MARTINS, C. E.; MONTEIRO, J. P. Locke (1632-1704) Vida e Obra. São Paulo: Editora Abril, $2^{\circ}$ edição, 1978. (Coleção Os Pensadores).

RIBEIRO, J. R. Apresentação a Norbert Elias. In: ELIAS, N. O processo civilizador. Uma historia dos costumes. Trad. Ruy Jungmann. Rio de Janeiro: Jorge Zahar Ed., 1994. $1 \mathrm{v}$.

\footnotetext{
${ }^{1}$ Formada em Pedagogia pela UNICENTRO, Guarapuava-PR

${ }^{2}$ Professor Adjunto do Departamento de Pedagogia da UNICENTRO, Guarapuava-PR
}

Recebido em 23/02/2011

Aprovado em 31/03/2011 